\title{
Differenz
}

Revista internacional de estudios heideggerianos y sus derivas contemporáneas

AÑO 1 NÚMERO 0: JULIO DE 2014. e-ISSN: 2386-4877 - DOI: 10.12795/Differenz.2014.i00.02

[pp. 11-15]

\section{El carisma de un joven profesor inconformista: la fuerza y la magia de Ser y tiempo.}

\section{Jesús Adrián Escudero}

\section{Universidad Autónoma de Barcelona}

Todavía hoy en día, Ser y tiempo sigue siendo un título mágico, compuesto de dos palabras intrigantes que, en su compleja sencillez, intenta repensar la pregunta fundamental de la historia de la filosofía: la pregunta por el ser. El secreto de Ser y tiempo y de su constante presencia cultural y filosófica radica en su particular estatuto. Ser y tiempo no elabora una teoría filosófica entre otras, sino que afronta el reto de pensar a fondo la crisis en la que se encuentra la filosofía. ¿Cómo afronta Heidegger este reto? Principalmente retomando el problema fundamental que ha caracterizado el pensamiento occidental: el problema del ser. Pero lo hace de una manera peculiar, haciendo confluir en él las inquietudes fundamentales de la época contemporánea: el desencantamiento del mundo moderno, la crisis de los valores tradicionales, el declive de la metafísica, la huída de los dioses, el dominio de la técnica, la hegemonía de la racionalidad instrumental y la búsqueda de nuevos recursos simbólicos para el hombre. En este sentido, Ser y tiempo se convierte en un preciso sismógrafo capaz de detectar con sorprendente precisión los corrimientos y las fallas de la era contemporánea, ofreciéndonos una radiografía exacta de la conciencia ética y moral de nuestro tiempo. De ahí su perenne actualidad, incluso en pleno siglo XXI.

Ser y tiempo tiene la capacidad, como comenta Susan Sontag a propósito de la fotografía, de arrancar las escamas secas de la visión habitual y, con ello, de crear una 
nueva forma de ver la realidad. ${ }^{1}$ En un tono intenso y apasionado, solícito y distante a la vez, alerta al detalle sin perder de vista el enfoque general, Ser y tiempo nos permite aprehender el mundo social tal cual es, incluidas sus miserias. La filosofía puede ser benigna, pero también es experta en crueldad a la hora de retratar los síntomas de una sociedad enferma, ociosa y decadente. Un crudo diagnóstico de la realidad, que, a su manera, ya había avanzado Nietzsche en las Consideraciones intempestivas al retratar la sociedad cultural alemana como una época dominada por profesores y tecnócratas, militares y funcionarios. Desde este punto de vista, Ser y tiempo participa plenamente del clima de desasosiego intelectual, de inhospitalidad existencial y de desazón espiritual de una época dominada por el ocaso de los héroes. Encontramos múltiples retratos de una sociedad fragmentada y falta de ídolos en obras coetáneas como El hombre sin atributos, de Robert Musil, La montaña mágica, de Thomas Mann, Ulises, de James Joyce, La metamorfosis, de Franz Kafka, y, de una manera muy gráfica, en El grito, de Edvard Munch, y en la película El Gabinete del Dr. Caligari, dirigida por Robert Wiene.

Así pues, no es de extrañar que ante este desolador panorama de la sociedad alemana emerjan espontáneamente preguntas relacionadas de una u otra manera con el sentido de la existencia humana. ¿Qué hacer ante una civilización que navega a la deriva? ¿Cómo escapar a una racionalidad técnica que calcula todas las variables de la existencia humana, que elimina toda huella de individualidad, que somete la voluntad personal al orden causal de las ciencias? El espíritu se siente aprisionado y desconfía de un discurso positivista que pretende construir una sociedad ideal y gobernar racionalmente el curso de la historia. La vida necesita abrirse paso y romper con falsas concepciones del mundo. Hay que volver la mirada hacia la realidad y hacer frente a la compleja cuestión de cómo volver a captar la inmediatez de la experiencia vivida. Eso significa poner en marcha un enorme esfuerzo de destrucción y creación de un nuevo lenguaje filosófico que supere los encorsetamientos conceptuales de la ciencia y la metafísica. Heidegger entiende los conceptos de la filosofía como un ataque a toda clase de certeza y de confianza en el mundo. En algunos momentos uno no puede dejar de escuchar en el joven Heidegger la voz del yo transgresor del protagonista de la novela de Dostoievski, Memorias del subsuelo, que reclama a un yo independiente y autónomo. Ese yo del subsuelo, como la vida ateorética de la que habla Heidegger en sus primeros cursos de Friburgo, rechaza el mundo euclidiano del racionalismo positivo que pretende resolver la complejidad de los problemas humanos con el procedimiento exacto de la lógica y de la aritmética. Se trata simplemente de reivindicar la singularidad de cada individuo sin conformarse con

1Cf. SONTAG, S., Sobre la fotografía, Edhasa, Barcelona, 1981, pp. 109ss. 
ser una tecla del piano. En definitiva, hay que practicar una constante hermenéutica de la sospecha para devolver al individuo la capacidad de pensamiento y de acción.

Se precisa de hombres con carisma capaces de renovar las viejas estructuras de pensamiento y de comportamiento. La filosofía debe responder a las cuestiones fundamentales de la existencia humana, aunque ello suponga transgredir el orden establecido. Vivir filosóficamente equivale a vivir arriesgadamente y pensar contra las normas prefijadas. El joven profesor se hace eco de esta llamada, asumiendo ya en sus primeras lecciones de 1919 el reto de elaborar una nueva idea de la filosofía. Nos hallamos, como comenta Heidegger con cierto tono de dramatismo, ante la encrucijada que decide sobre "la vida o la muerte de la filosofía en general, ante un abismo: o bien nos precipitamos en la nada (...), o bien logramos dar el salto a otro mundo.» ${ }^{2}$ Estamos ante uno de los momentos filosófica y personalmente más decisivos de la vida de Heidegger. Por una parte, se consuman su ruptura con el sistema del catolicismo y su matrimonio protestante con Elfredi Petri y, por otra, se detectan claros síntomas de distanciamiento con respecto a su sólida formación teológica y neokantiana que apuntan hacia la elaboración de una hermenéutica de la vida fáctica. En este sentido, Karl Löwith retrata con agudeza la peculiar personalidad del joven Heidegger: "Jesuita por su educación, se volvió protestante por reacción, dogmático escolástico por su formación, pragmático existencial por su experiencia, teólogo por tradición y ateo como investigador.» ${ }^{3}$ Diferentes rostros de una persona que intenta aprehender un fenómeno tan misterioso, resbaladizo y nebuloso como el de la existencia humana en su desnuda facticidad. La vida se presenta al joven Heidegger como un enigma que pide ser comprendido. El desciframiento de ese enigma marca el rumbo de un temprano itinerario filosófico que habrá de desembocar gloriosamente en su gran libro, Ser y tiempo (1927).

En este sentido, esta obra magna puede leerse en clave de una novela filosófica de formación que, al igual que otras novelas de la época, reflexiona sobre el significado del ser humano en una era dominada por la ciencia, poniendo de relieve el sometimiento del individuo a fuerzas más poderosas que lo anulan, empequeñecen y manipulan hasta el punto de perder de vista el sentido de su propia existencia. Heidegger era bien consciente de la importancia que los filósofos alemanes conceden al «mito del héroe». La Fenomenología del espíritu de Hegel y el Así habló Zaratustra de Nietzsche representan quizá el ejemplo más claro. Ello explica en parte que la noción heideggeriana del «Dasein propio y auténtico» comparta algunos elementos de ese mito: desde la huída de la caída

2 HEIDEGGER, M., Die Idee der Philosophie und das Weltanschauungsproblem (GA 56/57), Vittorio Klostermann, Frankfurt del Meno, 1987, p. 63.

3 LöWITH, K., Mein Leben in Deutschland vor und nach 1933, Metzer, Stuttgard, 1986, p. 45. 
en la impropiedad, la afirmación radical del individuo y el reconocimiento de la finitud humana hasta la confrontación y la transformación de uno mismo.

En Ser y tiempo nos encontramos con el Dasein como protagonista de una trama que se estructura en tres actos: en un primer momento, hallamos a un Dasein cómodamente instalado en las certezas de la vida cotidiana, que sabe desenvolverse práctica y eficazmente con las normas de comportamiento colectivamente reconocidas, que comparte un mismo horizonte de valores y de expectativas con la gente que le rodea, que se siente protegido por la sociedad a la que pertenece; en un segundo momento, este mundo familiar en el que el Dasein se siente como en casa entra inesperada y repentinamente en crisis, provocando la desorientación y la perplejidad de un Dasein que se encuentra por primera vez en su vida colocado delante del mundo sin capacidad de respuesta, sin asideros donde agarrarse, flotando en un océano ignoto y sin rumbo, suspendido en la nada más absoluta y preso de la angustia; y en un tercer momento, ese Dasein toma conciencia de su situación errática, asume su condición de arrojado y decide retomar las riendas de su existencia proyectando un modelo de vida propio que lucha contra la fatal inercia a volver a caer preso de las anónimas redes de la cotidianidad. Heidegger quiere que sus lectores se precipiten en el gran vacío, que oigan el susurro fundamental de la vida y combatan el aburrimiento existencial de la época.

Ese será uno de los hilos conductores de las interesantísimas lecciones del semestre de invierno de 1929/30 Los conceptos fundamentales de la metafísica. Mundo - Finitud - Soledad. En estas lecciones, consideradas por algunos como la gran obra secreta de Heidegger, ${ }^{4}$ el aburrimiento se convierte en todo un evento, en el que el mundo no tienen ningún contenido, en el que nos colocamos ante el abismo, en el que por lo regular se apodera de nosotros el horror del vacío: «¿Al final llegamos a la situación de que un profundo aburrimiento nos lleva de aquí para allá, a manera de una niebla silenciosa, en los abismos del Dasein?» (GA 29/30, 119). Llegados a ese punto, no hay más que una salida: despertar y tomar conciencia de que no hay nada de importancia, a no ser que lo haga uno mismo. Paradójicamente, el instante de esta resolución brota del aburrimiento mismo y le pone fin. ${ }^{5}$

4 Cf. SAFRANSKI, R., Un maestro de Alemania. Heidegger y su tiempo, Tusquets, Barcelona, 1997, p. 241.

5 Para las sugestivas interpretaciones fenomenológicas en torno a las tres modalidades del aburrimiento -a saber, el aburrirse con algo, el aburrirse con ocasión de algo y el aburrirse anónimo sin más -, véase HEIDEGGER, M, Die Grundbegriffe der Metaphysik (GA 29/30), Vittorio Klostermann, Frankfurt del Meno, 1983, pp. 117-249. 
Heidegger responde a este problema desde una perspectiva totalmente nueva: un análisis de la vida humana y su peculiar capacidad de hacer frente a su inherente tendencia a la caída. El análisis de la existencia humana que se lleva a cabo en Ser y tiempo y, por ende, en las lecciones previas, es en el fondo un análisis que se vuelve contra la tendencia que muestra la vida a caer una y otra vez presa de las redes de la opinión pública con el ánimo de imprimirle una forma exitosa, como si la vida fuera una obra de arte a la que Ser y tiempo intenta dar una forma bella. Desde este punto de vista, me gusta leer esta obra fundamental del siglo XX como invitación a realizar un viaje interior, un viaje que siempre tiene algo de una odisea plagada de obstáculos y peligros -unos desconocidos y otros conocidos- que debemos sortear con éxito para conducir nuestra vida a buen puerto. 